\title{
Especialidades Médicas - Dermatologia
}

\author{
Valéria Aoki', Lívia Salgado², Denise Miyamoto³
}

\section{Quando e como decidiu pela especialidade}

Minha escolha pela Dermatologia foi feita durante o internato, quando considerei meus interesses e aptidões e as características de cada especialidade. A Dermatologia, além de envolver as habilidades clínicas é também especialidade cirúrgica e compreende o atendimento a vários tipos diferentes de doenças (congênitas e adquiridas, inflamatórias e infecciosas, tumores benignos e malignos). Além disso, o dermatologista é responsável não só pela avaliação da pele, mas também da mucosa oral e genital, pêlos, cabelos e unhas.

O exame dermatológico é um verdadeiro trabalho de investigador, devendo ser completo e minucioso; nesse momento avalia-se o padrão e a distribuição das lesões, buscam-se informações que possibilitam determinar se a lesão é aguda ou crônica, se tem relação com doenças sistêmicas, quais as possíveis hipóteses diagnósticas e qual o tratamento mais adequado, na maioria das vezes independentemente da anamnese.

\section{Preconceito}

Como todas as especialidades, existe uma idéia caricata do dermatologista como um médico que trata doenças simples que serão resolvidas com cremes e corticóides, ou preocupado apenas com estética. A verdade é que a Dermatologia é uma especialidade extremamente ampla, com doenças de baixa e alta complexidade, responsáveis por um grande impacto na qualidade de vida dos pacientes, por se localizarem no órgão mais visível do corpo.

\section{Perfil dos atendimentos}

Os casos atendidos no consultório são geralmente de baixa e média complexidade. Pacientes com dermatoses mais graves, como síndrome de Stevens-Johnson, necrólise epidérmica tóxica, com lesões cobrindo áreas extensas do corpo, como na psoríase eritrodérmica, ou com infecções profundas, habitualmente requerem internação para tratamento. Qualquer que seja a gravidade, para que o dermatologista tenha sucesso no atendimento, é necessária uma formação universitária e especialização de qualidade. Além disso, a busca constante por aperfeiçoamento, atualização dos conhecimentos e uma boa relação médico-paciente são bases fundamentais para uma excelente prática clínica.

\section{Dificuldades iniciais da carreira}

Como em outras especialidades médicas, uma das dificuldades no início da carreira é a inserção no mercado de trabalho. No Estado de São Paulo, há mais de dois mil especialistas membros da Sociedade Brasileira de Dermatologia (SBD). Para ser considerado dermatologista é preciso cursar a residência médica em um serviço credenciado à SBD - há vinte e uma instituições cadastradas no Estado de São Paulo - e conseguir aprovação na prova para obtenção do título de especialista.

Algumas opções de emprego disponíveis ao concluir a residência são: atender no consultório de outros colegas, prestar concurso público, fazer credenciamento com convênios e seguradoras, realizar interconsultas para pacientes em internação

1. Graduada pela FMUSP - 1978, Residência Médica em Dermatologia pelo HC-FMUSP - 1991, Professora Doutora do Departamento de Dermatologia da FMUSP.

2. Médica graduada pela Faculdade de Medicina da USP - 2006, Residência Médica em Dermatologia no HC-FMUSP, 2010, Médica Pesquisadora na Dermatologia do HC-FMUSP.

3. Médica graduada pela Faculdade de Medicina da USP - 2006, Residência em Dermatologia pelo HC-FMUSP - 2011, Médica Pesquisadora na Dermatologia do HC-FMUSP. 
hospitalar, trabalhar na indústria farmacêutica e abrir consultório próprio.

A maioria dos dermatologistas no início da carreira começa a atender na clínica de outros colegas, pela possibilidade de adquirir mais experiência, maior facilidade para conseguir pacientes e dificuldade para abrir consultório próprio, dado o elevado custo inicial e de manutenção do mesmo. Trabalhar em hospitais, com planos privados de saúde e na indústria farmacêutica geralmente requerem a indicação de outros médicos. Além disso, os convênios costumam exigir o pagamento de uma taxa de adesão que inviabiliza o credenciamento.

\section{Mitos sobre a Dermatologia}

Existem muitos mitos sobre a Dermatologia, sendo que o principal deles envolve a remuneração, a qual se supõe ser maior que das demais especialidades por envolver a medicina estética. Na realidade, a falta de regulamentação para procedimentos estéticos possibilita sua realização por diversos médicos de outras especialidades que não cirurgia plástica e dermatologia, e até mesmo por fisioterapeutas e outros profissionais não médicos que realizam cursos de pós-graduação espalhados pelo país. Isso tem incentivado a proliferação de centros de estética com ou sem supervisão médica. O extremo dessa situação é a venda de pacotes de tratamento com desconto em sites de compra em grupo. Essa oferta de serviços realizados por não especialistas, que desconhecem as indicações, contra-indicações e resultados de cada técnica produz uma concorrência desleal e, mais grave ainda, proporciona um risco à saúde dos pacientes.

\section{Remuneração}

A remuneração na carreira é bastante variável. No inicio, a maioria dos profissionais tem mais de um vínculo empregatício. Atualmente, o valor de uma consulta pelos convênios é de 20 a 60 reais e da cirurgia ambulatorial entre 50 e 150 reais (sendo que em consultórios de colegas muitas vezes recebe-se metade deste valor); empregos nas instituições públicas podem pagar de 2500 a 4500 reais por 20 horas semanais. O valor de uma consulta particular depende de cada dermatologista. Vale ressaltar que as altas taxas de impostos contribuem significativamente para reduzir a renda líquida dos médicos de todas as especialidades. Em suma, a remuneração inicial é determinada pela dedicação e por quanto, como e onde cada dermatologista se dispõe a trabalhar. 